\title{
$D A R$, a New RhD Variant Involving Exons 4, 5, and 7, Often in Linkage With $c e A R$, a New Rhce Variant Frequently Found in African Blacks
}

\author{
By M.B. Hemker, P.C. Ligthart, L. Berger, D.J . van Rhenen, C.E. van der Schoot, and P.A. Maaskant-van Wijk
}

\begin{abstract}
The highly polymorphic Rh system is encoded by 2 homologous genes RHDand RHCE. Gene rearrangements, deletions, or point mutations may cause partial $D$ and CE antigens. In this study, a new RHD variant, DAR, and a new RHCE variant, ceAR, are described in 4 Dutch African Blacks. Serologically, DAR showed weaker reactions with a monoclonal antibody and polyclonal antiserum against $D$. The DAR phenotype was characterized by complete loss of at least 9 of 37 Rh D epitopes. Erythrocytes expressing ceAR were all typed as VS- ${ }^{-} \mathbf{V}^{+}$. DNA analysis showed a partial D allele with only 3 mutations: C602G (exon 4), T667G (exon 5), and T1025C (exon 7). The ceAR allele carried G48C (exon 1), a hybrid exon 5 (A712G, C733G, A787G, and T800A), and A916G (exon 6). To study the frequency of these variants, 326 South-African
\end{abstract}

$\mathbf{T}$ HE RHESUS (Rh) BLOOD-GROUP system is clinically important, because antibodies against $\mathrm{Rh}$ antigens are involved in hemolytic disease of the newborn, hemolytic transfusion reactions, and autoimmune hemolytic anemia.

The Rh system is complex; as many as 45 different antigens have been serologically defined. ${ }^{1,2}$ These antigens are carried by nonglycosylated, nonphosphorylated polypeptides. The Rh polypeptides are predicted to have 12 transmembrane-spanning domains with intracellular $\mathrm{N}$ - and $\mathrm{C}$-termini, resulting in 6 extracellular loops on which the $\mathrm{Rh}$ antigens are located. ${ }^{3,4}$ Two highly homologous genes, RHCE and $R H D$, encode the Rh antigens. Both genes are localized on chromosome 1p34.3p36.1 and are inherited together. ${ }^{5}$ RHCE gives rise to the $\mathrm{C} / \mathrm{c}$ and $\mathrm{E} / \mathrm{e}$ polymorphisms. $R H D$ encodes the $\mathrm{RhD}$ antigen. Total or partial deletion of the $R H D$ gene can result in the D-negative phenotype. ${ }^{6-10}$ In non-Whites, it has been found that D negativity can appear in individuals carrying the complete $R H D$ gene. ${ }^{11,12}$

The most immunogenic Rh antigen is the Rh D antigen, comprising at least 30 epitopes. ${ }^{13,14}$

Partial D phenotypes, characterized by loss of epitopes, can arise from replacement of RHD exons by their RHCE counterparts, as has been shown in $\mathrm{D}^{\mathrm{III}}, \mathrm{D}^{\mathrm{III}}, \mathrm{D}^{\mathrm{IVb}}, \mathrm{D}^{\mathrm{Va}}, \mathrm{D}^{\mathrm{VI}}$, DFR, and DBT and by point mutations in the RHD gene that occur in $\mathrm{D}^{\mathrm{II}}$, $\mathrm{D}^{\mathrm{IVa}}, \mathrm{D}^{\mathrm{VII}}$, DHMi, DNU, and DHR. Frequencies of $\mathrm{D}^{\mathrm{VII}}, \mathrm{D}^{\mathrm{VI}}$, $\mathrm{D}^{\mathrm{IV}}, \mathrm{D}^{\mathrm{V}}, \mathrm{D}^{\mathrm{II}}-\mathrm{like}$, and DFR are 1:900, 1:6,800, 1:10,000, $1: 30,000,1: 30,000$, and 1:60,000, respectively, as established with serological methods in a White population. ${ }^{15}$ Alloantibodies may be produced against missing epitopes in individuals expressing rhesus D variants when exposed to the complete antigen by blood transfusion or during pregnancy.

Three types of $R H C E$ variants have been described. ${ }^{16}$ Single point mutations are found in VS, V, $\mathrm{C}^{\mathrm{w}}, \mathrm{C}^{\mathrm{x}}$, and $\mathrm{Rh}: 26 . R H C E$ exon replacements, in which exons of different alleles of $R H C E$ are exchanged, were found in $\mathrm{r}^{\mathrm{G}} \mathrm{r}$ and a variant in which exon 1 and intron 1 of the c-allele are replaced by the corresponding part of the C-allele. Finally, replacement of RHCE exons by their $R H D$ equivalents may occur, as is found in $\mathrm{D}--, \mathrm{Dc}-$, $\mathrm{R}_{\mathrm{o}}{ }^{\mathrm{Har}}, \mathrm{R}^{\mathrm{N}}$, and partial E. As in $R H D$ variants, these exon
Blacks was screened genomically. Of the 326 donors, 16 $(4.9 \%)$ carried the DAR allele, $20(6.1 \%)$ the ceAR allele, and $14(4.3 \%)$ both mutated alleles. Five of these donors (1.5\%) had the DAR phenotype, indicating that they carried the DAR allele homozygously or next to a D-negative allele. Immunogenicity of the D antigen for individuals with the DAR phenotype was proven, because 1 of the 4 Dutch individuals produced allo-antibodies against $D$ after multiple transfusions with D-positive blood. In a multiethnic society, the prevalence of this $D$ phenotype will increase and is therefore relevant in transfusion practice and in prevention of hemolytic disease of the newbom.

(C) 1999 by The American Society of Hematology.

replacements or mutations not only result in loss of epitopes, but may also account for the formation of new epitopes.

In the present report, we describe a new partial D antigen, called DAR, expressed in 4 unrelated Dutch women of African Black origin. In these 4 individuals, a variant RHCE gene, called $c e A R$, was also found. That more African Blacks are carrier of the mutated $R H D$ gene was suggested by the fact that 3 of these 4 women were noticed in a routine pregnancy screening. Thereafter, blood was sent for confirmation of the rhesus typing to the Central Laboratory for Blood Transfusion (CLB; Amsterdam, The Netherlands). We also screened 326 African Black donors from the South African Blood Transfusion Service (Johannesburg, South Africa) for DAR and $c e A R$.

\section{MATERIALS AND METHODS}

Samples

EDTA anticoagulated blood samples were obtained from 4 unrelated African Black women (identification numbers 3308, 3424, 3895, and 4413). Three samples were noticed because of weak D expression during routine pregnancy screening and were sent to the CLB for confirmation. A blood sample of individual 4413 was referred to our lab because antibodies were detected. Red blood cells (RBCs) of these individuals were Rh phenotyped according to standard protocols with

From the Laboratory for Transfusion Science, Bloodbank Rotterdam, Rotterdam, The Netherlands; the Department of Immunohematology, $C L B$ and Laboratory for Experimental and Clinical Immunology, Academic Medical Center, University of Amsterdam, Amsterdam, The Netherlands; the Department of Hematology, University Hospital Rotterdam, Rotterdam, The Netherlands; and the Department of Hematology, Academic Medical Center, Amsterdam, The Netherlands. Submitted June 1, 1999; accepted August 17, 1999.

Address reprint requests to P.A. Maaskant-van Wijk, PhD, Bloodbank Rotterdam Location Dordrecht, Laboratory for Transfusion Science, Albert Schweitzerplaats 5, 3318 AS Dordrecht, The Netherlands.

The publication costs of this article were defrayed in part by page charge payment. This article must therefore be hereby marked "advertisement" in accordance with 18 U.S.C. section 1734 solely to indicate this fact.

(C) 1999 by The American Society of Hematology.

0006-4971/99/9412-0019\$3.00/0 
monoclonal antibody (MoAb) MS-201 (CLB) recognizing D epitope 6/7 (9-epitope model; equal to D-epitope 12 in the 37-epitope model), a polyclonal reagent (anti-D with bromelain as enhancer; CLB), and MoAbs (all obtained from CLB) recognizing C (MS 24), c (MS 32), E (MS 260), or e (MS 21, MS 63). Polyclonal reagents 97-501639 (patient serum) and Q-sera were used to phenotype VS and V, respectively. The presence of the low incidence antigen $\mathrm{D}^{\mathrm{W}}$, thus far only found in $\mathrm{D}^{\mathrm{Va}}$, was tested with an anti-Rh23 by C. Green and G. Daniels (International Blood Group Reference Laboratory, Bristol, UK). Phenotyping for partial D was performed with a panel of selected MoAbs with known epitope specificity (Third International Workshop on Monoclonal Antibodies against Red Cell and Related Antigens, 1996, Nantes, France). ${ }^{17}$ RBCs of donor 3424 were sent to the IBGRL (Bristol, UK) for confirmation.

In the blood sample of individual 4413 , erythrocyte antibodies were present with the specificity of anti-D, $-\mathrm{C},-\mathrm{E},-\mathrm{Fy}^{\mathrm{a}},-\mathrm{Jk}^{\mathrm{a}},-\mathrm{M}$, and $-\mathrm{Sl}^{\mathrm{a}}$. This individual suffered from sickle cell anemia and received multiple transfusions over the years. Adsorption-elution techniques were used to determine whether the anti-D antibodies were alloantibodies or autoantibodies.

Blood samples of 326 South-African Black donors were randomly collected by the South African Blood Transfusion Service in Johannesburg (courtesy of J. Hooydonk, Johannesburg, South Africa). Seven donors were serologically typed as RhD negative, and all other donors were $\mathrm{RhD}$ positive.

\section{cDNA Sequence Analysis}

White blood cell-reduced RBCs were enriched with reticulocytes as described before. ${ }^{18,19}$ RNA was isolated from the reticulocyte-enriched fraction..$^{20} \mathrm{cDNA}$ was obtained by reverse transcriptase-polymerase chain reaction (RT-PCR; using Superscript II RNAse H-RT; GIBCO BRL, Gaithersburg, MD), and full-length amplification was performed with consensus primers as described in Table 1. PCR products were ligated into pGEM-T vector (system I; Promega, Madison, WI), and the vectors were introduced into competent Escherichia coli by electroporation. ${ }^{21}$ Inserts were cycle-sequenced automatically (ABI-PRISM 377, DNA sequencer; Perkin-Elmer, Norwalk, CT) on both strands.

\section{Genomic DNA Analysis}

Genomic DNA was isolated from peripheral blood leukocytes with a DNA isolation kit (Puregene, Minneapolis, MN).

Sequence analysis. On genomic DNA, exon-specific PCRs were used. All primers are listed in Table 1. Exons 4 to 5 (including intron 4) and 7 were amplified with $R H D$-specific primers $\left(\mathrm{R} 496 / \mathrm{Rex} 5 \mathrm{AD}_{2}\right.$ and R973/R1068, respectively) and cycle-sequenced automatically (ABIPRISM 377, DNA sequencer). Exon 5 and exon 6 were amplified with consensus primers (Rex5S $/$ Rex5A and Rex6S/Rex6A, respectively); PCR products were subcloned and sequenced.

PCR assays. Five PCR allele-specific primer amplifications (ASPAs) were designed specifically for detection of mutations. Primerset R31/ R147 and internal control primer R-15 (all 3 primers located in exon 1) were used to recognize the $\mathrm{C}$-specific nucleotide at position $48 .{ }^{22} \mathrm{An}$ ASPA specific for $C E$ nucleotides at position 602 and 667 (primerset R581/R667) was developed to amplify intron 4 . We applied an exon 5 ASPA, using a $C E$-specific sense primer (R678) and a $D$-specific antisense primer $\left(\operatorname{Rex} 5 \mathrm{AD}_{2}\right)$, to detect a hybrid exon 5 . An exon 5 to 6 ASPA was used to amplify intron 5 with the $C E$-specific sense primer R678 in exon 5 and the $D$-specific antisense primer R933 in exon 6 . An exon 6 to 7 ASPA (primerset R973/R1044) with a $D$-specific sense primer in exon 6 and a $C E$-specific antisense primer in exon 7 was developed to detect the $C E$-specific mutation in $D$-exon 7.

RHD-specific multiplex PCR. RHD exons 3, 4, 5, 6, 7, and 9 were amplified with $R H D$-sequence specific primers in a 1-reaction mixture assay as described before. ${ }^{23}$

Restriction fragment length polymorphism of RH intron 5. To determine the origin of the intron 5 of the ceAR allele, intron 5 was amplified with sense primer R716 (specific for nt $733 \mathrm{G}$, present in the $\mathrm{CE}$ allele of $\mathrm{VS}^{+}$individuals and in the $\mathrm{D}$ allele) and antisense primer

Table 1. Nucleotide Sequences and Positions of Primers

\begin{tabular}{|c|c|c|c|c|c|}
\hline Primer & & Sequence & $\begin{array}{l}\text { Annealing } \\
\text { Time and } \\
\text { Temperature }\end{array}$ & Amplicon & Specificity \\
\hline $\mathrm{R}-15$ & Sense & 5'tatctagagacggacacaggATGAGC3' & $1 \mathrm{~min}, 60^{\circ} \mathrm{C}$ & Exon 1 & Consensus \\
\hline R31 & Sense & 5'СGCTGCCTGCCCCTCTGC $3^{\prime}$ & & Exon 1, Cspecific & Cspecific: nt 48 \\
\hline R147 & Antisense & 5'TTGATAGGATGCCACGAGCCCC3' & & & Consensus \\
\hline R496 & Sense & 5'CACATGAACATGATGCACA $3^{\prime}$ & $1 \mathrm{~min}, 55^{\circ} \mathrm{C}$ & Exon 4 to 5 & D specific: nt 514 \\
\hline $\operatorname{Rex} 5 \mathrm{AD}_{2}$ & Antisense & 5'сасCTTGCTGATCTTACC3' & & & D specific: nt 787 \\
\hline R581 & Sense & 5'ACGGAGGATAAAGATCAGAG3' & $1 \mathrm{~min}, 55^{\circ} \mathrm{C}$ & Intron 4, CE specific & CE specific: nt 602 \\
\hline R667 & Antisense & 5'CTCAGCAGAGCAGAGTTGAC3' & & & CE specific: nt 667 \\
\hline $\operatorname{Rex}_{5} \mathrm{~S}_{2}$ & Sense & $5^{\prime} \operatorname{cctctctggccccaggCGCC} 3^{\prime}$ & $1 \mathrm{~min}, 55^{\circ} \mathrm{C}$ & Exon 5 & Consensus \\
\hline $\operatorname{Rex} 5 \mathrm{~A}$ & Antisense & $5^{\prime}$ cagcgecctgctcac3' & & & Consensus \\
\hline R678 & Sense & 5'CTGCTGAGAAGTCCAATCC $3^{\prime}$ & $1 \mathrm{~min}, 55^{\circ} \mathrm{C}$ & Exon 5, CE-D hybrid & CE specific: nt 707 \\
\hline $\operatorname{Rex} 5 \mathrm{AD}_{2}$ & Antisense & 5'cacCTTGCTGATCTTACC3' & & & $D$ specific: nt 787 \\
\hline R678 & Sense & 5'CTGCTGAGAAGTCCAATCC $3^{\prime}$ & $1 \mathrm{~min}, 55^{\circ} \mathrm{C}$ & Exon 5 to $6, C E-D$ hybrid & CE specific: nt 707 \\
\hline R933 & Antisense & 5'GTACTTGGCTCCCCCGAC3' & & & $D$ specific: nt 916 \\
\hline R716 & Sense & 5'TCAACACCTACTATGCTG3' & $1 \mathrm{~min}, 55^{\circ} \mathrm{C}$ & Intron 5 & VS and $D$ specific: nt 733 \\
\hline R870 & Antisense & 5'AGAAGGGATCAGGTGACACG3' & & & Consensus \\
\hline Rex6S & Sense & $5^{\prime}$ gctatttctttgcag3' & $30 \mathrm{~s}, 48^{\circ} \mathrm{C}$ & Exon 6 & Consensus \\
\hline $\operatorname{Rex} 6 \mathrm{~A}$ & Antisense & $5^{\prime}$ tgtctagtttcttca $3^{\prime}$ & $\alpha$ taq added & & Consensus \\
\hline R973 & Sense & 5'AGCTCCATCATGGGCTACAA3' & $1 \mathrm{~min}, 67^{\circ} \mathrm{C}$ & Exon 6 to $7, D-C E$ hybrid & D specific: nt 992 \\
\hline R1044 & Antisense & 5'CACCAGCAGCACAATGTAGG3' & & & CE specific: nt 1025 \\
\hline R973 & Sense & 5'AGCTCCATCATGGGCTACAA3' & $1 \mathrm{~min}, 55^{\circ} \mathrm{C}$ & Exon 7 & D specific: nt 992 \\
\hline R1068 & Antisense & 5'ATTGCCGGCTCCGACGGTATC3' & & & D specific: nt 1068 \\
\hline $\mathrm{R}-15$ & Sense & 5'tatctagagacggacacaggATGAGC3' & $1.5 \mathrm{~min}, 55^{\circ} \mathrm{C}$ & Full-length cDNA & Consensus \\
\hline R1339 & Antisense & 5'gcgtttctcacgtacaaatgc $3^{\prime}$ & & & Consensus \\
\hline
\end{tabular}

The sequences of the oligonucleotides are given in capital letters when exon sequences are indicated and in small letters when intron sequences are indicated. 
R870 (consensus primer). This product was D-specifically digested with restriction enzyme Apa I (New England Biolabs Inc, Beverly, MA) and analyzed by electrophoresis in a $1 \%$ agarose gel.

Southern blot analysis. Ten micrograms of DNA from all donors was digested with the endonuclease BamHI and, after electrophoresis, transferred to a nitrocellulose membrane. Blots were hybridized with a ${ }^{32} \mathrm{P}$-labeled $R H$ full-length cDNA (kindly provided by Dr D. Anstee, IBGRL). The results were visualized by autoradiography.

\section{PCR Conditions}

All PCR assays were performed in a Perkin-Elmer Cycler Model 480 on $200 \mathrm{ng}$ of cDNA or gDNA in a total volume of $50 \mu \mathrm{L}$. Reaction mixtures contained $50 \mathrm{ng}$ of each primer, $0.2 \mathrm{mmol} / \mathrm{L}$ of each dNTP (Pharmacia, Uppsala, Sweden), and 2 U of Taq DNA polymerase (Promega) in the appropriate buffer supplemented with $1.5 \mathrm{mmol} / \mathrm{L}$ $\mathrm{MgCl}_{2}$.

PCR conditions were 1 cycle of 5 minutes at $95^{\circ} \mathrm{C}$, followed by 35 cycles of 1 minute at $95^{\circ} \mathrm{C}$, with an annealing time and temperature as described in Table 1 and, depending on the size of the expected product, the extension time at $72^{\circ} \mathrm{C}$ varied between 45 seconds and 2.5 minutes. Extension was completed during 5 minutes at $72^{\circ} \mathrm{C}$.

RESULTS

Serology

Individuals 3308, 3424, 3895, and 4413 were serologically typed as $\mathrm{C}^{-}, \mathrm{c}^{+}, \mathrm{E}^{-}$, and $\mathrm{e}^{+}, \mathrm{VS}^{-}$, and $\mathrm{V}^{+}$. $\mathrm{RBCs}$ of these 4 individuals showed weaker reactions with anti-D MoAb MS201 and polyclonal anti-D antiserum than did normal Rh (D)-positive control cells. Therefore, with restricted screening protocols, these donors might be considered as expressing weak D. However, extensive serological studies of all 4 individuals showed a new partial D pattern (Table 2) in which 9 of the 37 epitopes were completely missing and 6 of the 37 epitopes showed different results with several MoAbs. These results were confirmed by Joyce Poole's laboratory of the IBGRL. $\mathrm{RBCs}$ of these 4 donors did not carry the low incidence antigen $\mathrm{D}^{\mathrm{W}}$.

The antibodies present in the serum of patient 4413 were characterized with the adsorption-elution technique. It was shown that antibodies directed against D were present, among other antibodies. With agglutination studies it was shown that these antibodies did not react with her own erythrocytes or with the erythrocytes of other donors with the DAR phenotype, but did react with erythrocytes from normal D-positive donors, indicating that these antibodies are allo-anti-D.

\section{cDNA Sequence Analysis}

Sequencing of cDNA from 1 individual (identification no. 3424) showed the presence of 3 different transcripts (Fig 1). At least 3 clones per different transcript were completely sequenced: (1) a normal ce transcript; (2) a ce-like transcript carrying G48C (Trp16Cys) in exon 1; A712G (Met238Val), C733G (Leu245Val), A787G (Arg263Gly) and T800A (Met267Lys) in exon 5; and A916G (Ile306Val) in exon 6; and (3) a $D$-like transcript carrying C602G (Thr201Arg) in exon 4, T667G (Phe223Val) in exon 5, and T1025C (Ile342Thr) in exon 7.

\section{Genomic DNA Analysis}

To confirm the mutations found in cDNA of individual 3424, as well as to show the presence of the mutations in the other 3

\begin{tabular}{|c|c|c|c|}
\hline \multicolumn{2}{|c|}{ Epitope Model } & \multirow[b]{2}{*}{ Nantes } & \multirow[b]{2}{*}{ DAR } \\
\hline $1-9$ & $1-37$ & & \\
\hline 1 & 1 & LHM 169/81 & \pm \\
\hline 1 & 2 & LHM 70/45, LHM 174/102 & - \\
\hline 2 & 3 & LOR12-E2, LORE & \pm \\
\hline 2 & 4 & LOR28-7E6 & - \\
\hline 3 & 5 & LOR11-2D9, LHM 76/55, H41.11B7, H41 & + \\
\hline 4 & 6 & LOR17-6C7 & + \\
\hline \multirow[t]{2}{*}{5} & 7 & CAZ7-4C5 & - \\
\hline & & HIRO-6 & \pm \\
\hline 5 & 10 & $\begin{array}{l}\text { AUB-2F7/Fiss, MAR-1F8 } \\
\text { C205-29, CLAS1-126, BS229, BS231 }\end{array}$ & $\begin{array}{l}- \\
\pm\end{array}$ \\
\hline 5 & 11 & 819 & - \\
\hline $6 / 7$ & 12 & $\begin{array}{l}\text { 175-2, LOR17-8D3, P3AF6, RUM-1, } \\
\text { MS201, P3×61 }\end{array}$ & \pm \\
\hline \multirow[t]{2}{*}{$6 / 7$} & 13 & $\begin{array}{l}\text { D-89/47, 17010C9, LOR28-21D3, } \\
\text { H2D5D2F5 }\end{array}$ & \pm \\
\hline & & F5S & + \\
\hline $6 / 7$ & 15 & $\begin{array}{l}\text { D-90/7, D-90/17, NOI, SAL20-12D5, } \\
\text { LHM50/2B, LHM 169/80, BIRMA-DG3, } \\
\text { BIRMA-D56, L87.1G7, D10 }\end{array}$ & \pm \\
\hline \multirow[t]{2}{*}{$6 / 7$} & 17 & $\begin{array}{l}\text { HeM-92, NaTH53-2A7, P3F17, HIRO-I, } \\
\text { HS114 }\end{array}$ & - \\
\hline & & B9A4B2, NaTH28-3C11, BS232 & \pm \\
\hline \multirow[t]{2}{*}{$6 / 7$} & 18 & LHM59/20, T3D2F7, P3F20 & - \\
\hline & & $\begin{array}{l}\text { HG/92, LHM 50/3.5, LHM 59/25, HM } 10 \\
\text { ID6-H8 }\end{array}$ & $\begin{array}{l} \pm \\
+\end{array}$ \\
\hline \multirow[t]{3}{*}{$6 / 7$} & 21 & VOL-3F6 & - \\
\hline & & D-90/12, BRAD5 & \pm \\
\hline & & HIRO-2 & + \\
\hline 8 & 22 & LHM 59/19 & - \\
\hline \multirow[t]{10}{*}{9} & 23 & P3×21223B 10 & - \\
\hline & & $\begin{array}{l}\text { BIRMA-D6, P3G6, MS26, HIRO-4, HIRO-7, } \\
\text { HIRO-8 }\end{array}$ & \pm \\
\hline & 31 & NOU & - \\
\hline & 32 & ZIG-189 & - \\
\hline & 33 & NaTH87-4A5 & - \\
\hline & 34 & LORA & - \\
\hline & 35 & SALSA-12 & - \\
\hline & 36 & NAU3-2E8, BTSN6, LHM 76/59 & \pm \\
\hline & & NAU6-4D5 & + \\
\hline & 37 & 822, HIRO-3 & + \\
\hline
\end{tabular}

The serology was performed as described before. ${ }^{24}$ This pattern was found in all 9 individuals expressing DAR homozygously or next to a D-negative allele. These results were confirmed by J oyce Poole's laboratory of the IBGRL.

Abbreviations: -, negative MoAb reaction; \pm , positive MoAb reaction, but weaker than that of normal Rh (D)-positive control cells; +, positive MoAb reaction.

individuals, 3308, 3895, and 4413, analysis on genomic DNA was performed. All of these results were in full concordance with the cDNA analysis.

From individual 4413, not only the exons of interest, but also all exons were amplified from genomic DNA and subsequently cycle-sequenced. No other mutations were found.

The mutations found in the $c e$-like transcript were confirmed on genomic DNA by an ASPA that recognized the C-specific nucleotide at position 48 ; by sequence analysis of $c e$-exon 5 that 
Transcript 1: normal ce allele

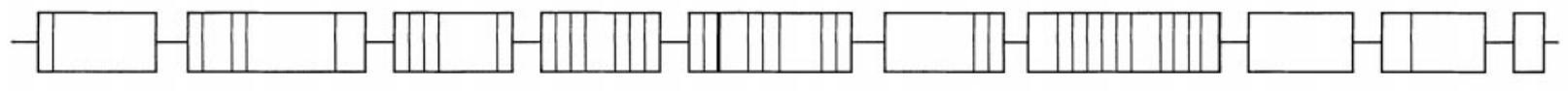

Transcript 2: partial ce allele: $c e A R$

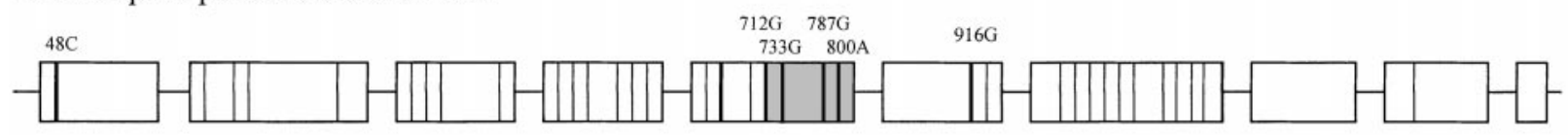

Transcript 3: partial D allele: $D A R$

$602 \mathrm{G} \quad 667 \mathrm{G}$

$1025 \mathrm{C}$

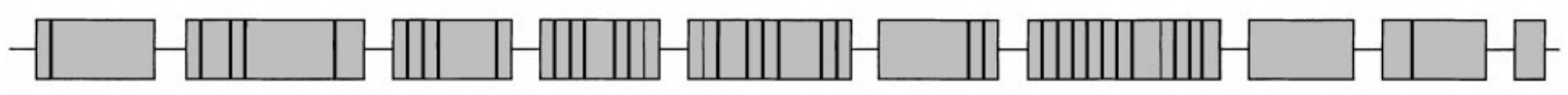

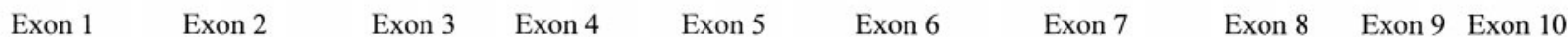

Fig 1. Transcripts as found by sequencing cDNA. Nucleotides derived from the RHCE sequence are represented by a thin line, whereas nucleotides derived from the $R H D$-specific sequence are represented by a fat line. $R H D$-specific exons or exon parts are represented by a gray rectangle, whereas those of $R H C E$ are given in white.

showed the mutations A712G, C733G, A787G, and T800A; and by sequence analysis of $c e$-exon 6 that showed A916G. The $c e$ origin of intron 5 was indicated by a remaining uncut part, after D-specific digestion with Apa I of the 1,791-bp product, obtained after $D / V S$-specific amplification of intron 5.

The mutations found in the $D$-like transcript were detected by sequence analysis of $R H D$-exon 4 to 5 and exon 7 . Beside the mutations $\mathrm{C} 602 \mathrm{G}$ and $\mathrm{T} 667 \mathrm{G}$, sequence analysis showed a normal $D$-intron $4^{24}$ and the T1025C mutation in D-exon 7 . To show that only the mutated $\mathrm{D}$ transcript was present, in the absence of a normal D allele, the $R H D$-specific multiplex was performed. The 200-bp internal control fragment from the $\beta$-actin gene was amplified from all 4 DNA samples. Amplification products from exons $3,6,7$, and 9 were detected, whereas exons 4 and 5 were not amplified.

Southern blot analysis. The BamHI digestion pattern of the genomic DNA from the 4 individuals $(3308,3424$, 3895, and 4413) showed no difference in the Rh patterns compared with those of a normal D-positive donor.

\section{Screening of the South-African Black Donors}

In 56 of the 326 South-African Black donors (17.2\%), the RHCE intron 4 PCR demonstrated the $2 C E$-specific nucleotides in the exon 4 and 5 of the $R H D$ gene, with a D intron 4 in between. All 56 of these donors were serologically $\mathrm{RhD}$ positive. In 16 of these 56 donors, the presence of T1025C was proven by the $D-C E$ hybrid exon 6 to $7 \mathrm{PCR}$, indicating the presence of the $D A R$ allele.

Because a linkage between the $D A R$ and the $c e A R$ allele was assumed, we tested all 326 donors for the presence of the $c e A R$ allele. In 20 of the 326 donors $(6.1 \%)$, the $C E-D$ hybrid exon 5 PCR and the $C E-D$ hybrid exon 5 to 6 PCR gave positive results, indicating the presence of a $c e A R$ allele. Of those 20 donors, 14 were also carriers of the DAR allele. Thus, 2 donors carried the $D A R$ allele without the $c e A R$ allele and 6 donors carried the $c e A R$ allele without the $D A R$ allele.

Five of the 14 donors carrying the $D A R$ and $c e A R$ allele
(1.5\%) had the deviant RHD multiplex PCR pattern, missing exon 4 and 5. This indicates that these 5 donors were either homozygous for the DAR or carried DAR on 1 allele and lacked RHD on the other. The results found on gDNA of these 5 donors were serologically confirmed and gave with all 5 the same 37-epitope pattern as shown in Table 2.

In DNA of the 40 donors carrying only the C602G and T667G mutations in exon 4 and 5 of the RHD gene and not the T1025C mutation in exon 7, the $C E-D$ hybrid exon 5 PCR and the $C E-D$ hybrid exon 5 to 6 PCR gave negative results, indicating the absence of the $c e A R$ allele. One of these 40 donors showed the deviant RHD multiplex PCR pattern, missing exons 4 and 5.

\section{DISCUSSION}

In this study, a newly discovered D variant named DAR that occurs frequently in African Blacks is described. This new D variant consists of a $D$ allele with 3 point mutations on polymorphic sites, in which $D$-specific nucleotides are replaced by $C E$-specific ones. These mutations are located in exon 4 (nt 602), exon 5 (nt 667), and exon 7 (nt 1025). The 4 probands also had a variant $c e$ allele, called $c e A R$. This allele had a $\mathrm{C}$-specific mutation on nt 48 in exon 1, a hybrid exon 5 in which the polymorphic sites between nt 712 and nt 800 were replaced by $\mathrm{D}$-specific nucleotides, and a D-specific point mutation on polymorphic site nt 916 in exon 6 .

This new D variant was previously described by us as ARRO-I. ${ }^{25}$ At that time, sequence analysis was not completed. Further analysis showed the mutation in exon 7 and the mutant $c e$-allele in these individuals.

Serologically, this new D variant showed weaker reactions with a monoclonal anti-D and with polyclonal antiserum used for routine screening, indicating weak D expression. The genomic features of the new variant have much resemblance with the recently described weak D type 4, in which the mutations $\mathrm{C} 602 \mathrm{G}$ and $\mathrm{T} 667 \mathrm{G}$ are also present, but the mutation $\mathrm{T} 1025 \mathrm{C}$ is not. ${ }^{26}$ However, with extensive serological testing, 
the D characteristics of the DAR phenotype gave a different, not previously described pattern of serological reactions with MoAbs. The loss of epitopes, as well as the finding of allo-anti-D formation in an individual with the DAR phenotype, indicates that we are dealing with a new qualitative $\mathrm{D}$ variant with low expression. In 1 of the 40 South African Black donors in whom PCR-based analysis showed the mutation in exon 4 and 5 but not in exon 7, the expression was not masked by the presence of a normal D gene. This donor is expected to present the weak D type 4 phenotype. Preliminary serological results of this donor suggest a quantitative instead of a qualitative loss of epitopes, as can be expected from the results of Wagner et al. ${ }^{26}$ This is an intriguing observation in view of the effect of the mutation in exon 7 for the loss of epitopes. An explanation for this phenomenon can perhaps be found in the fact that the mutations in exon 4 and 5 do not change the polarity of the amino acids in the protein. In contrast, the transmembranal mutation in exon 7 causes the incorporation of a hydrophilic amino acid (Thr) instead of a hydrophobic amino acid (Ile). This might result in a severe change in the conformation of the Rh protein, explaining the described loss of epitopes. In the future, transfection studies will be performed to study this phenomenon in detail.

The loss of so many D epitopes in DAR is the result of only 3 mutations in $R H D$, because from the variant ce-allele only addition of D epitopes can be expected. The mutations at the $3^{\prime}$ end of exon 4 and the $5^{\prime}$ end of exon 5 of the $\mathrm{D}$ allele are due to point mutations. This is suggested by the presence of a normal D intron 4, as shown by sequence analysis. However, aberrant nucleotides may occasionally be introduced if incorrect mismatch repair of the heteroduplex DNA takes place during gene conversion. ${ }^{27}$ So, the DAR mutations on the $3^{\prime}$ side of exon 4 and the $5^{\prime}$ side of exon 5 also could be due to the occurrence of heteroduplex repair, rather than to spontaneous point mutations. The same phenomenon has been described for the glycophorins $\mathrm{A}$ and $\mathrm{B}$, which are also encoded by highly homologous genes. ${ }^{27}$

The variant $c e$-gene, $c e A R$, is characterized by a mutation in exon 1 , a hybrid exon 5, and a mutation in exon 6 . The presence of G48C (Trp16Cys), the C-specific nucleotide in exon 1, without expression of this antigen, frequently occurs in African Blacks. ${ }^{28}$ The $D$-specific nucleotide found in exon 6 of the $C E$ allele is probably caused by a point mutation or might be due to heteroduplex repair (see above), because restriction site analysis suggested a normal $c e$-intron 5 . Besides the $c e A R$ allele, a complete $c e$-allele was also found, so it was not possible to test the loss of $c e$-epitope expression. All 4 individuals were expressing the rare $\mathrm{VS}^{-}, \mathrm{V}^{+}$phenotype. Daniels et al ${ }^{29}$ has previously described that the VS mutation (G733, in exon 5) surrounded by $D$-specific nucleotides in exon 5 and the V-specific nucleotide 1006G (Gly336) provided the $\mathrm{VS}^{-}, \mathrm{V}^{+}$ serotype. In this study, RHCE exon 6 was not sequenced. Therefore, $4 \mathrm{VS}^{-}, \mathrm{V}^{+}$samples of African Black donors (provided by Dr G.L. Daniels, IBGRL) were sequenced, and, indeed, these samples also showed the mutation in exon 6 as well as the $\mathrm{C}$ mutation (G48C). These results suggest that the most common genetic basis of the $\mathrm{VS}^{-}, \mathrm{V}^{+}$phenotype is the $c e A R$ variant. Furthermore, these 4 donors also carried the DAR allele.

The 4 original probands in whom this new serological reaction pattern was found all proved to be of African Black origin. No Whites carrying this variant have been found so far during routine screening. This suggested that more African Blacks might be carriers of these genes. Therefore, a group of 326 South-African Blacks was screened by genomic PCR. We found that $4.9 \%$ of this group are carriers of a $D A R$ allele. Five donors $(1.5 \%)$ had the gene homozygous or in combination with a D-negative allele, as was shown by the absence of the amplification products from exons 4 and 5 in the multiplex PCR. These donors also had the same serological partial D pattern as was shown in the $37 \mathrm{D}$-epitope model. The fact that so many South-African Blacks are carriers of this gene suggests that these donors have an evolutionary advantage, as described for Duffy involving malaria. ${ }^{30}$ So far, no correlations between $\mathrm{Rh}$ phenotypes and the occurrence of malaria have been found. However, these studies have been performed on immunologically recognized antigens, whereas this new variant is primarily recognized at the DNA level. The frequency of the DAR phenotype $(1.5 \%)$ in the African Black population is much higher than the frequency of $\mathrm{D}$ variants in the White population $(0.1 \%$ to $0.001 \%)$ and therefore might have an impact on monoclonal reagent design. Testing the African Blacks for the presence of the $c e A R$ showed that $6.1 \%$ were carriers of this allele.

The finding that the first 4 individuals tested expressed both variant alleles suggested that these 2 genes were inherited en bloc. By screening the 326 African Blacks, we expected to find only donors carrying both mutated alleles or both normal alleles. The screening results did not confirm this idea, because, besides donors with both variant alleles, also donors with only the $D A R$ or $c e A R$ allele were found. Nevertheless, the incidence of the combination is much higher than is expected to occur by chance, indicating linkage of DAR and $c e A R$.

Individuals with the DAR phenotype may form anti-D antibodies when exposed to a complete D antigen. Despite the loss of so many epitopes, a complete $\mathrm{D}$ antigen does not seem to be highly immunogenic for individuals expressing DAR. Otherwise, the highly frequent DAR variant should have been recognized much earlier. A possible explanation for this low responsiveness may be that the footprints of most anti-Rh (D) antibodies are related to one another, as was published recently. ${ }^{31}$ It is postulated that, in the allo-immune response against the Rh (D) antigen in different individuals, a similar and restricted pathway is used. It is tempting to speculate that, in this variant, the apparent low immunogenicity of the complete $\mathrm{D}$ antigen is due to the fact that the most common pathway could not be used, because these B cells have been clonally deleted or have become anergic to avoid self-reactivity. Probably a less-common pathway has produced the anti-Rh (D) made by the multitransfused donor 4413 .

The clinical significance of these anti-D antibodies in this individual is not yet clear. Nevertheless, pregnant women and recipients of blood transfusions expressing the DAR variant should be regarded as D negative. As donors, people expressing DAR should be carefully distinguished from D-negative donors by the use of selected reagents, because allo-immunization is likely to occur when administering erythrocytes expressing the DAR variant to D-negative recipients. Therefore, donors expressing DAR should be regarded as D positive. Hemolytic disease of the newborn could occur in fetuses expressing DAR when carried by an immunized D-negative mother or in fetuses with 
the complete D antigen carried by mothers with the DAR phenotype. Therefore, in the future, anti-D monoclonals for immunoprophylaxis should be guaranteed to cover this new variant, especially because of the high incidence of this new variant in a multiethnic society in which $D$ negativity is found more frequently than in the original African Black population. In addition, the chance of getting a population with an even higher frequency of people expressing DAR is increased, because the expression will not be masked by the presence of a normal D allele.

\section{ACKNOWLEDGMENT}

J. Hooydonk (South African Blood Transfusion Service) was very helpful with the collection of samples from the African Black population. The authors thank him for the collaboration. We are grateful to J. Poole, C. Green, and G. Daniels from the IBGRL for their very kind collaboration on this manuscript. We thank M.A.M. Overbeeke, A.E.G.Kr. von dem Borne, and D. Roos for their comments on the manuscript.

\section{REFERENCES}

1. Issit PD: The blood group system: Additional complexities. Immunohematology 10:109, 1994

2. Daniels G: Human Blood Groups. Oxford, UK, Blackwell Science, 1995

3. Chérif-Zahar B, Le Van Kim C, Blanchard D, Bailly P, Hermand P, Salmon C, Cartron JP, Colin Y: Molecular cloning and protein structure of a human blood group Rh polypeptide. Proc Natl Acad Sci USA 87:6243, 1990

4. Avent ND, Butcher SK, Liu W, Mawby WY, Mallinson G, Parsons $\mathrm{SF}$, Anstee DJ, Tanner MJA: Localization of the $\mathrm{C}$ termini of the $\mathrm{Rh}$ (rhesus) polypeptides to the cytoplasmatic face of the human erythrocyte membrane. J Biol Chem 267:15134, 1992

5. Chérif-Zahar B, Mattéi MG, Le Van Kim C, Bailly P, Cartron J-P, Colin Y: Localization of the human Rh blood group gene structure to chromosome region 1p34.3-1p36.1 by in situ hybridization. Hum Genet 86:398, 1991

6. Colin Y, Chérif-Zahar B, Le van Kim C, van Huffel R, Cartron JP: Genetic basis of the RhD-negative blood group polymorphism as determined by Southern blotting. Blood 82:651, 1991

7. Hyland CA, Wolter LC, Saul A: Three unrelated Rh D gene polymorphisms identified among blood donors with Rhesus Ccee $\left(r^{\prime} r^{\prime}\right)$ phenotypes. Blood 84:321, 1994

8. Umenishi F, Kajii E, Ikemoto S: Molecular analysis of Rh polypeptides in a family with $\mathrm{Rh} \mathrm{D}$ positive and $\mathrm{Rh} \mathrm{D}$ negative phenotypes. Biochem J 299:207, 1994

9. Faas BHW, Beckers EAM, Wildoer P, Ligthart PC, Overbeeke MAM, Zondervan HA, von dem Borne AEGKr, van der Schoot CE: Molecular background of VS and weak C expression in blacks. Transfusion 37:38, 1997

10. Blunt T, Daniels G, Carrit B: Serotype switching in a partially detected $R H D$ gene. Vox Sang 67:397, 1994

11. Daniels G, Green C, Smart E. Differences between Rh-negative Africans and RhD-negative Europeans. Lancet 350:862, 1997 (letter)

12. Okuda H, Kawano M, Iwamoto S, Tanaka M, Seno T, Okubo Y, Kajii E: The RHD gene is highly detectable in RhD-negative Japanese donors. J Clin Invest 100:373, 1997

13. Scott M, Voak D, Jones JW, Avent ND, Liu W, Hughes-Jones N, Sonneborn H: A structural model for RhD epitopes based on serological and DNA sequence data from partial D phenotypes. Transfus Clin Biol $3: 391,1996$
14. Scott M: Rh serology coordinator's report. Transfus Clin Biol 3:333, 1996

15. Flegel WA, Wagner FF: The frequency of RHD protein variants in Caucasians. Transfus Clin Biol 3:10S, 1996

16. Faas BHW, Beckers EAM, Maaskant-van Wijk PA, Overbeeke MAM, van Rhenen DJ, von dem Borne AEGKr and van der Schoot CE: Molecular characterization of qualitative $\mathrm{Rh}$ variants. Biotest Bull 5:439, 1997

17. Annex 2: Rh antibodies. Third International Workshop and Symposium on monoclonal antibodies against human red blood cells and related antigens. Transfus Clin Biol 6:525, 1996

18. Murphy JR: Influence of temperature and method of centrifugation on the separation of erythrocytes. J Lab Clin Med 82:334, 1973

19. Simsek S, de Jong CAM, Cuypers HThM, Bleeker PMM, Westers TM, Overbeeke MAM, Goldschmeding R, van der Schoot CE, von dem Borne AEGKr: Sequence analysis of cDNA derived from reticulocyte mRNAs coding for Rh polypeptides and demonstration of E/e and C/c polymorphisms. Vox Sang 67:203, 1994

20. Chomczynski P, Sacchi N: Single step method of RNA isolation by acid guanidium thiocyanate-phenol-chloroform extraction. Anal Biochem 162:156, 1987

21. Sambrook J, Fritsch EF, Maniatis T: Molecular Cloning: A Laboratory Manual. Cold Spring Harbor, NY, Cold Spring Harbor Laboratory, 1989

22. Faas BHW, Beckers EAM, Simsek S, Overbeeke MAM, Pepper $\mathrm{R}$, van Rhenen DJ, von dem Borne AEGKr, van der Schoot CE: Involvement of Ser 103 of the Rhesus polypeptides in the G epitope formation. Transfusion 36:506, 1996

23. Maaskant-van Wijk PA, Faas BHW, de Ruijter JA, Overbeeke MA, von dem Borne AEGKr, van Rhenen DJ, van der Schoot CE: Genotyping of $R H D$ by multiplex polymerase chain reaction analysis of six $R H D$-specific exons. Transfusion 38:1015, 1998

24. Avent ND, Martin PG, Armstrong-Fisher SS, Liu W, Finning KM, Maddocks D, Urbaniak SJ: Evidence of genetics underlying $\mathrm{RhD}-$, weak $\mathrm{D}(\mathrm{Du})$, and partial $\mathrm{D}$ phenotypes as determined by multiplex polymerase chain reaction analysis of the RHD gene. Blood 89:2568, 1997

25. Hemker M, Ligthart PC, Faas BHW, von dem Borne AEGKr, van der Schoot, van Rhenen DJ, Maaskant-van Wijk PA: ARRO-I, a new partial D phenotype involving exon 4 and 5. Vox Sang 74:1331, 1998 (suppl 1)

26. Wagner FF, Gassner C, Muller ThH, Schonitzer D, Schunter F, Flegel WA: The molecular basis of weak D phenotypes. Blood 93:385, 1999

27. Huang $\mathrm{CH}$, Blumenfeld: MNSs Blood groups and major glycophorins: Molecular basis for allelic variation, in Blood Cell Biochemistry, vol 6. Molecular Basis of Major Blood Group Antigens. New York, NY, Plenum, 1995, p 153

28. Faas BHW, Christiaens GCML, Maaskant-van Wijk PA, Zondervan HA, von dem Borne AEGKr, van der Schoot CE: The reliability of prenatal RH and Kell genotyping: A prospective study in different ethnic groups. Prenatal Diagnosis (submitted)

29. Daniels GL, Faas BHW, Green CA, Smart E, Maaskant-van Wijk PA, Avent ND, Zondervan HA, von dem Borne AEGKr, van der Schoot CE: The RH VS and V blood group polymorphisms in Africans: A serological and molecular analysis. Transfusion 38:951, 1998

30. Gelpi AP, King MC: Duffy blood group and malaria. Science 191:1284, 1976

31. Chang TY, Siegel DI: Genetic and immunological properties of phage-displayed human anti-Rh (D) antibodies: Implications for the Rh (D) epitope topology. Blood 91:3066, 1998 